\title{
Cuando los dioses nos abandonan. El miedo a la oscuridad en el mundo antiguo.
} Miguel Requena Jiménez' ${ }^{7}$

\section{RESUMEN}

Cuando los dioses nos abandonan. El miedo a la oscuridad en el mundo antiguo. La oscuridad, bien por la llegada de la noche, por la presencia de una densa niebla, o por la ocultación del sol o luna a consecuencia de un eclipse, fue valorada por las sociedades antiguas como la máxima expresión de la ausencia de protección divina.

Palabras-clave: Noche; miedo; dioses.

\section{ABSTRACT}

When the gods leave us. The fear of darkness in the Ancient World. The darkness, either by the arrival of the night, by the presence of a dense fog, or the occultation of the Sun or moon as a result of an eclipse, was valued by ancient societies as the ultimate expression of the absence of divine protection.

Key words: Night; Fear; gods.

\author{
El dia tiene miedo de perder su claridad \\ cuando viene la noche que expande sus tinieblas. \\ Pocos animales no cierran los párpados \\ $y$ los enfermos aumentan en su dolor. \\ Los malhechores quisieran que durase todo el año \\ para que sus delitos bubiesen encubrimiento, \\ pero yo que vivo en sin par tormento \\ y sin hacer daño, quisiera que pasase pronto. \\ Ausiàs March (VALENCIA, S. XV).
}

\footnotetext{
1Doctor en Historia Antigua por la Universitat de Valencia. Profesor Titular del Departamento de Historia de la Antigüedad y de la Cultura Escrita de la Universitat de Valencia. Académico Correspondiente de la Real Academia de la Historia (España). Premio de la Fundación Pastor de Estudios Clásicos (2000). Profesor Invitado en las Universidades

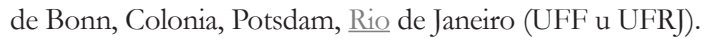

Ci. Huma. e Soc. em Rev., RJ, EDUR, v. 35, n 1, jan / jun, p. 42-56, 2013.
} 


\section{INTRODUCCIÓN}

La noche ha sido durante miles de años un momento especialmente crítico en el devenir cotidiano de los hombres. La pérdida de la capacidad visual que para los humanos supone la oscuridad de la noche, reducía sus posibilidades de defensa ante el acechoy ataque de toda una serie de depredadores, tales como lobos, chacales, felinos, etc. La noche era para los primeros homínidos un período de tiempo crítico, de debilidad ante predadores mucho mejor adaptados que ellos a las características de ese momento del día. Era, por tanto, un período de tensión, de temor y de alerta. No resulta difícil por ello suponer la rápida asociación de los conceptos noche-oscuridad-negro-peligro-muerte por

parte del hombre prehistórico. Una relación que todavía presenta vestigios en la percepción que de la noche tienen las sociedades modernas. Por el contrario y consecuentemente, el día, iluminado por la cálida luz del Sol, se identificaría con conceptos positivos tales como el de seguridad, alegría, blanco, claridad o vida. Nos encontramos ante una de las grandes polaridades primordiales de las sociedades antiguas ya señalada por E. Durkheim.

El contraste entre día y noche, luz y oscuridad, blanco y negro también afectó decisivamente a las creencias de los hombres. El día, y sobre todo el Sol, astro que marcaba los límites de este periodo temporal, fueron rápidamente asociados a valores tales como la justicia, la verdad, la razón, el bien, la salud, la vida, la civilización o la protección (DÖLGER, 1918; DEONNA, 1965; RUSSELL, 1995; PASTOUREAU, 2009; DAUGE, 1981). Por ello el día se convirtió rápidamente en el dominio de los dioses celestes caracterizados por dichos valores y que el Sol fuera incorporado a la iconografía y simbología de los mismos. Divinidades como Zeus/ Júpiter, Jahweh, Apolo, Mitra, Cristo, etc., son dioses de la claridad, de la luz, del día, con evidentes connotaciones solares (WALLRAFF, 2010). Sin olvidar que según una etimología transmitida por Varrón, incluso la propia denominación de la divinidad -dius/diuus- remite a la luz diurna, al cielo luminoso, en claro contraste con la oscuridad nocturna (VARRO, LL. VI 4). Igualmente, como primer cómputo en la medición del tiempo, el contraste día/noche asignó a ambos períodos toda una serie de valores antagónicos relacionados con la acción humana. Frente a la actividad o el esfuerzo característicos del claro día, momento aprovechado para la caza, la recolección, el viaje, o la actividad social entre otros muchos actos, la noche oscura y fría era el momento del descanso, de la inactividad, del sueño, de la muerte temporal del hombre que espera la resurrección al nuevo día, e incluso de la muerte eterna. No es extraño, en consecuencia, que en el entramado mitológico de los griegos, Nyx -la negra noche- sea la madre de los hermanos gemelos Hypnos -el sueño- y Thanatos -la muerte-, y que al menos desde los poemas de Homero y Hesiodo, haya existido una reacción instintiva a asimilar la muerte al sueño (ARIÈS, 1977, 
30-31). Así, numerosos lécitos de fondo blanco griegos presentan escenas en las que los genios alados Hymnos y Thanatos aparecen como porteadores del muerto en los ritos fúnebres (DIEZ DE VELASCO, 1995), sin olvidar que los antiguos cristianos conceptuaron el sueño nocturno como una muerte cotidiana (SAXER, 1980). Actualmente el oficio de "Completos" finaliza con la oración "que el Señor nos conceda una noche tranquila y una muerte santa".

\section{PELIGROS NOCTURNOS}

Para las sociedades antiguas la noche es el dominio de toda la pléyade de seres malignos. En ese momento la injusticia, el mal, la enfermedad, la muerte, la barbarie o la mentira, valores antagónicos a los señalados para el día, se instalan entre los hombres que, desprovistos temporalmente de la protección de los dioses celestes, pueden ser atacados inesperadamente por los fantasmas u otros seres innominables e informes (RUSSELL, 1995).

Es entonces cuando hacen su presencia todos los espectros que por doquier existen, todos los lémures, todos los manes, todas las larvas, todas las apariciones nocturnas, todas las figuras espantosas que surgen de las piras funerarias, todas las visiones terrorificas de los sepulcros, con los que Apuleyo (APOL. LXIV 1) amenaza a su enemigo Emiliano. Propercio (IV 7), en sus elegías afirma que en la noche caminamos vagando, la noche libera las sombras encerradas, el mismo Cérbero vaga, quitado el cerrojo.

Horacio (Ep. II 2), Porfirio (ad Hor. II 2) o Varrón en Servio (ad Aen. V 64; VI 152), entre otros muchos autores clásicos, hablan de nocturnos lemures. Espíritus errantes de los muertos, que no pueden descansar en el Infierno por haber fallecido de muerte violenta antes del día fijado por las Parcas, o por no haber recibido las debidas honras fúnebres (JOBBÉ-DUVAL, 1924).

Es durante la noche y generalmente a través de su hijo, el sueño, cuando los dii inferii o los vengativos lémures se hacen visibles a sus familiares o asesinos para aterrorizarlos con su presencia y anunciarles su próxima muerte.

Es igualmente la oscuridad de la noche el momento aprovechado por ladrones y asesinos para cometer sus acciones. De ahí que la nocturnidad sea un agravante de la pena en la mayoría de códigos penales de todos los tiempos (Ley DE LAs Doce TABLAS, VIII 9; VIII 12 o VIII 26), o que en el Codex Theodosianus las reuniones nocturnas sean valoradas como especialmente peligrosas, pues se considera el momento oportuno para realizar invocaciones a las fuerzas del mal o a los muertos, y para la utilización de instrumentos mágicos o la ejecución de sacrificios funestos $(C T h$ $9,16,7.364)$. 
También las temibles Gelo, Mormo, Lamia o las voraces Estriges aprovechan la oscuridad de la noche para raptar y devorar a los niños indefensos. Y la noche es el momento en que las puertas del Hades se abren para dejar salir a los habitantes del reino de las sombras, entre las cuales se encuentran los démones de las enfermedades (GIL, 2004), las keres, creencia que fundamenta el atávico temor a caer enfermo durante la noche.

\section{LOS DIOSES TAMBIÉN DUERMEN}

Unos peligros y temores que no hacían más que expresar una peligrosa circunstancia: la ausencia temporal de protección divina.

En efecto, la noche no es sólo el momento en el que los hombres duermen, en el entramado mítico grecorromano, también los dioses quedan rendidos al poder del sueño y de su madre la noche.

En sus Diálogos de los dioses (4 (24), 1), Luciano de Samosata recoge la desazón de Hermes ante los muchos trabajos y servicios que debe llevar a cabo en el Olimpo. Unas tareas que incluso le dificultan el necesario descanso nocturno:

Por la mañana recién levantado tengo que barrer la sala del banquete, y luego de extender el cojín del diván poner en orden cada cosa, presentarme a Zeus y hacer llegar sus recados, corriendo todo el santo día para arriba y para abajo, y cuando vuelvo, manchado aún de polvo, servir la ambrosía. Y antes de que llegara el copero ese recién adquirido, tenía yo también que escanciar el néctar. Y lo peor del caso es que de todos soy el unico que no duerme por la noche, sino que entonces he de llevarle en comitiva las almas a Plutón, acompañar a los muertos y estar presente en la sesión del tribunal.

De Atenas nos ha llegado la siguiente inscripción con un himno matinal procedente del Asklepieion:
Despierta, Paieon Asclepio, soberano de pueblos
bijo del Letoida de la venerable Corónide, de suave corazón,
sacude el sueño de tus párpados y escucha las súplicas
de tus mortales, que en masa gozosos se propician
tu fuerza. Asclepio de suave corazón, primero a Hygieia
despierta y escucha, job! dios del grito del ie, tu bimno. Salud.
(IG II-III ${ }^{2}$ 34533). 
Así, en los templos, como el dedicado a Isis "las tareas matutinas daban comienzo cuando la divinidad se despertaba, ficción en la que participaba el 'borólogo', encargado de marcar el instante en el que habia de realizarse cada cosa y que justifica la existencia de clepsidras y otros instrumentos de medición del tiempo en algunos iseos (ALVAR, 2001). Tras ello el simulacro de la diosa era lavado, peinado y perfumado por numerosos sirvientes como si de un mortal se tratara tras despertar del nocturno sueño.

Como parece apuntar un fragmento de la Ilíada, los dioses pierden su poder ante la extraordinaria potencia de la Noche, considerada por numerosas cosmogonías el ser primigenio, origen del mundo (KIRK, 2003).

La Noche ayudada por su hijo el sueño es capaz de vencer a los dioses, incluso a Zeus. Así, Homero (Il. XIV 256-261) pone en boca del Sueño las siguientes palabras:
Zeus, al despertarse, se enojó y a mí
sobre todo me buscaba entre empellones a los dioses por su casa.
Y me habría hecho invisible, hundido en el ponto lejos del éter,
de no baberme salvado la Noche, que rinde a dioses y a hombres.

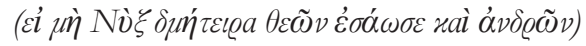
A ella me acogífugitivo, yél, a pesar de su ira, se contuvo
por respeto, para no hacer nada que desagradara a la veloz Noche.

Durante la noche los dioses duermen, y en consecuencia pierden su capacidad protectora. En dichas circunstancias la humanidad se siente sola, abandonada temporalmente por unas deidades que la protegen durante el día y por tanto expuesta a infinidad de amenazas.

Por ello, la llegada de la noche con todos los peligros impulsa a los hombres a buscar refugio en las ciudades, en las casas o incluso, en casos excepcionales, en los templos, (normalmente cerrados por la noche), ámbitos especialmente protegidos por toda una serie de límites apotropeos -como son las puertas-, iluminados por el fuego del hogar o de las velas -pequeños sustitutos del sol- y cercanos a los -dormidos- dioses protectores.

Burcardo de Worms (Decretorum libri XX) a principios del año mil todavía recuerda el miedo de muchas personas a salir de casa antes del amanecer:

¿Has creído lo que suelen creer algunos que, necesitando salir de casa antes de que amanezca, lo dejan para después y no se atreven, porque dicen que es peligroso salir antes del canto del gallo, y que los 
espiritus inmundos de la noche tienen poderes maléficos mayores antes del canto del gallo que después, y tiene más fuerza el gallo para abuyentarlos y vencerlos con su canto que la divina inteligencia que bay en el hombre con su fe y con el signo de la cruz?

Durante la Edad Media los monasterios intentaban evitar esa total oscuridad de la noche, manteniendo encendidas velas, linternas, antorchas y teas. Como nos informa O. Giordano (2001):

Al caer la noche las tinieblas más densas envolvian el gran centro urbano y el más pequeño y perdido pagus, la casa aristócrata y la cabaña del campesino; la oscuridad indicaba para todos la suspensión temporal y total de cualquier actividad pública y privada y el aplazamiento de cualquier compromiso. En los monasterios, en cambio, se puede decir que no habia diferencia entre el día y la noche; en estas "ciudades santas" el opus diuinum era perenne, ocupaba las 24 horas del día sin solución de continuidad. El canto del oficio en el coro no conocía largas pausas o interrupciones: incluso en las horas nocturnas la celda, el dormitorio, la iglesia, el claustro vivían la misma laboriosidad, resonaban con las mismas voces.

Hemos de entender con ello que el monasterio se convierte así en el único reducto de protección divina durante la noche, sustituyendo en la medida de lo posible la luz solar por la del fuego.

La situación se convierte en especialmente dramática cuando el anochecer cae sobre las personas en ámbitos incivilizados o no habitados por humanos, y entre éstos son particularmente peligrosos el desierto, el bosque y la montaña, o el mar. Lugares a donde los conjuros de todas las épocas suelen enviar los peligros o males que se acercan a una comunidad. En tales circunstancias, la presencia de seres malignos y de la muerte está asegurada y consecuentemente debemos prepararnos para superar la noche y esperar la protección del Sol que llega con el alba y el canto del gallo.

Ese miedo a la noche, a la desprotección divina, intensificaba la alegría de los hombres por la llegada del nuevo día. Una alegría que incluso se exteriorizaba en forma de canción. No olvidemos la importancia de las albás o albaradas religiosas en la tradición popular. Un ejemplo de ello es esta albá, que con diferentes versiones ha sido cantada durante siglos en numerosos pueblos de España:

\footnotetext{
Bendita la luz del día,

y el señor que nos la envía.

Bendito su gran poder

que nos ha dejado amanecer.

Bendita la luv,

bendita la cruve
} 


\author{
bendita la madre \\ que parió a Jesús. \\ Ay, Jesús, ya viene el alba; \\ sin Jesús nadie se salva; \\ sin Jesús no bay cosa buena; \\ venga Jesús enhorabuena; \\ a darle luz a mi alma. \\ Bendita la luv, \\ bendita la cruz:
}

Prudencio en su Himno para cuando canta el gallo (Himnos cotidianos, I 30-55), muestra claramente el contraste entre ambos períodos del día:

\footnotetext{
Mas desde la cima la voz magistral de Cristo nos advierte que la luzya está cerca, para que el sopor no subyugue nuestro espiritu, para que hasta el fin mismo de una vida indolente no oprima el sueño nuestro pecho, enterrado en el yerro y olvidado de su propia lu:

Dicen que los demonios deambulan felices en la oscuridad de las noches, aterrados por el canto del gallo, emprenden temerosa y desmandada buida.

Y es que la odiosa vecindad de la lur, salvadora y divina, desbarata el poso de las tinieblas y pone en fuga a los acólitos de la noche.

Présagos, ya saben que ésta es la señal de la esperanza de nuevo prometida, por la que nosotros, libres de sopor, esperamos la llegada de Dios.

Cuál es la fuerza de esta ave lo muestra a Pedro el Salvador, al predecir que, antes que el gallo cante, tres veces él ha de ser negado.

$Y$ es que el pecado acontece antes de que el pregonero de la luz inminente alumbre al género bumano y ponga fin al pecar.
}

La literatura y el cine de terror han sabido jugar con este atávico temor en infinidad de relatos y secuencias donde el peligro se inicia cuando el sol se oculta. Momento en el que el hombre se siente solo y desprotegido ante el sueño de los dioses.

\title{
UNA DENSA NIEBLA
}

Cualquier oscurecimiento, repentino o permanente, natural o artificial, acontecido a cualquier hora del día, también ha servido para evocar sentimientos similares a los de la oscura noche. Ahora bien, en este caso la ausencia de la protección divina no deriva del necesario sueño de los dioses, sino que suele reflejar el abandono voluntario de su tutela sobre un territorio, comunidad o persona. 
Sombría es la entrada al Hades. Alli ésta la ciudad y el país de los hombres cimerios, / siempre envueltos en nubes y en bruma, que el sol fulgurante/desde arriba jamás con sus rayos los mira ni cuando/encamina sus pasos al cielo cuajado de estrellas/ ni al volver nuevamente a la tierra del cielo (Od. XI 14-17), describe Homero la llegada de Ulises al Infierno para consultar al adivino Tiresias. Y es en las umbrosas entrañas de los bosques o en el interior de oscuras cuevas o cavernas, a través de las cuales también se puede acceder al infierno, donde la tradición y la literatura universal han situado la morada de seres fabulosos, en numerosos casos extremadamente peligrosos, tales como dragones, ogros, gigantes, cíclopes, enanos, etc.

El cine ha reflejado perfectamente este temor en películas como The Fog de John Carpenter (USA, 1979) o The Mist de Frank Darabont (USA, 2007). En la primera, los fantasmas de unos náufragos vengan sus muertes en el momento en el que brota una extraña niebla. En cambio, en la segunda, basada en la novela del mismo título de Stephen King (1983), son monstruos los que acechan en una densísima niebla que asedia a los personajes en un supermercado.

Bram Stoker en su fabuloso Drácula describe como la travesía del conde desde Transilvania a Londres estuvo acompañada por una perpetua niebla, la misma que caracteriza a la capital inglesa, símbolo de ateísmo e incredulidad, y por ello carente de la protección divina.

Las crónicas cuentan que entre los prodigios que acontecieron antes de la caída de Constantinopla en poder turco el 29 de mayo de 1453, "toda la ciudad quedó cubierta de una espesa niebla, fenómeno desconocido en estas latitudes en el mes de mayo. La Divina Presencia se ocultaba en la nube para encubrir su salida de la ciudad. Aquella noche, al disiparse la niebla, se observó un resplandor extraño sobre la cúpula de la gran iglesia de Santa Sofía (RUNCIMAN, 1973). La Divina Presencia había abandonado Constantinopla, dejándola a merced del invasor.

La percepción popular del poder imperial también se vio afectada por esta estructura ideológica. Dado que el poder es una gracia divina, el fin de un monarca fue valorado por las sociedades antiguas como la pérdida de la protección divina hacia esa persona. Dos ejemplos simbolizan claramente dicha circunstancia. Cuenta Suetonio en la biografía de Nerón que el emperador renunció a viajar a Alejandría porque el mismo día de su partida se vio turbado por un escrúpulo religioso y por la amenaza de un peligro. En efecto, al visitar Nerón el templo de Vesta, el borde de su toga le impidió alzarse y luego se levantó una niebla tan densa que le era imposible distinguir nada. 
Nam cum circumitis templis in aede Vestae resedisset, consurgenti ei primum lacinia obhaesit, dein tanta oborta caligo est, ut dispicere non posset (Suet. Nero. 19, 1).

Entre los presagios que anunciaron la muerte del emperador Cómodo (180-192 d.C.) la Historia Augusta señala que en las calendas de enero apareció en el circo repentinamente una densa niebla que lo oscurecía.

Et repentina caligo ac tenebra in circo Kalendis Ianuariis oborta (SHA, Comm, XVI 2). Ambos fenómenos anunciaban el próximo final de sus reinados.

\section{ECLIPSES}

Ciertos oscurecimientos también podían expresar una terrible realidad: la imposibilidad de los dioses para seguir manteniendo su tutela sobre una comunidad o persona. En este sentido el oscurecimiento más temido por las sociedades antiguas fue sin lugar a dudas el derivado de los eclipses, tanto de sol como de luna. Narra Quinto Curcio que días antes de la batalla de Gaugamela, la noche del 20 al 21 de septiembre del año 331:

Hacia la primera vigilia se produjo un eclipse de luna: comenzó el astro por perder su resplandor, después su claridad quedó mancillada al desparramarse un color de sangre; estando como estaban los soldados profundamente preocupados ante la inminencia de un peligro tan grande, vino a caer sobre ellos una ingente superstición y, como producto de ella, una especie de terror (IV 10, 2).

Poco antes de la salida de Pelópidas y los soldados contra el tirano Alejandro de Feras, campaña solicitada por una embajada de Tesalia y apoyada fervientemente por los tebanos, hubo un eclipse de sol, y la oscuridad se adueño de la ciudad en pleno día:

Y Pelópidas, al ver que todos estaban alterados por el fenómeno, creyó que no debía forzar a quienes estaban atemorizadosy desanimados, ni poner en peligro a siete mil ciudadanos, asi que partióponiéndose solo él a disposición de los tesalios con trescientos jinetes voluntarios y algunos extranjeros, a pesar de que los adivinos no lo permitian y los otros ciudadanos no compartían su buen ánimo (Plut. Pel. 31, 3-4).

Cuenta Livio que tras la dedicación del templo de Juno Moneta, bubo una lluvia de piedras y se vio a la noche extenderse en pleno día. Consultados los libros, como la población estab a dominada por el temor religioso, el senado acordó el nombramiento de un dictador para organizar unas fiestas (VII 28, 7). Y Claudiano, en su relación de todos los malos presagios que anunciaban la inminente invasión de los godos, destaca el terror que entre la población causaban los eclipses de luna (De bello Getico, 233-238). 
Como se puede apreciar en estos cuatro testimonios de los muchos que podríamos haber citado, los eclipses, tanto de sol como de luna, han generado en todas las sociedades antiguas unas reacciones de alarma y terror difícilmente comprensibles para un fenómeno natural que no supone consecuencias dramáticas para la población que lo contempla.

Frente a un terremoto, una inundación o incluso la caída de un rayo, el eclipse no causa destrucción, no acaba con la vida de ninguna persona, no altera el crecimiento de las cosechas ni la fertilidad de los ganados. ¿Por qué entonces ese pánico al oscurecimiento momentáneo del sol o de la luna? Evidentemente la respuesta debe buscarse en las estructuras ideológicas sobre las que desde épocas prehistóricas las sociedades antiguas articularon su percepción de la realidad:

Para unas poblaciones que todavía no han adquirido los instrumentos necesarios para protegerse de los peligros que supone la presencia de expertos depredadores como lobos, leones, osos u otras fieras, la noche es un momento crítico, de debilidad, de crisis, en la que estas poblaciones sufrían muchos más ataques y muertes que las causadas por la caída de un rayo, un terremoto o cualquier diluvio. La noche era inconmensurablemente más peligrosa para ellos que dichos fenómenos naturales. La oscuridad era el más claro indicio del abandono de la protección divina, y de ello sólo podían derivarse graves consecuencias.

Un eclipse expresaba el intento de los espíritus de la noche por acabar definitivamente con la leve luz que proporcionaba la luna, o incluso por apoderarse del dominio de los dioses protectores, el día, fenómeno que tiene su contrapartida en los destellos de luz que durante la noche anuncian el nacimiento o epifanía de un ser protector vencedor de la noche.

El temor a una victoria final de los espíritus del mal y a que una oscuridad eterna invadiera la vida de los hombres, llevaba a éstos últimos a participar con sus dioses protectores en esta dramática guerra (LUNAIS, 1979). Es así como se ha entendido la popular costumbre de que en el momento en el que se iniciaba un eclipse, los hombres golpearan objetos de bronce, hacían sonar las trompetas, gritaban y realizaban todo el ruido posible, con el objetivo de ayudar a los dioses ahuyentando a los espíritus malignos.

Así Livio compara el alboroto del inicio de una batalla con el clamor que es costumbre hacer en el silencio de la noche durante los eclipses de luna (XXVI 5, 9). Por ello el eclipse observado antes de la batalla de Pidna provocó que en el campamento macedonio bubo gritos y lamentos hasta que la luna apareció de nuevo con su propio brillo (Liv. XLIV 37, 9). Ovidio afirma que retumban en vano los bronces con que se la quiere auxiliar (Met. IV 332-333), en referencia a la luna. Juvenal al ironizar sobre el vozarrón de una mujer, declara: que nadie fatigue las trompetas ni las placas de cobre: ella sola se bastará para sacar a 
la luna del mal paso (VI 442-443). Séneca señala que el sol no tiene espectador más que cuando se eclipsa. Nadie observa la luna más que cuando se desvanece: entonces las ciudades lanzan gritos, entonces cada cual arma un gran griterio llevado de su estúpida superstición (Nat. VII 1, 2). Y Tácito en los Annales narra la siguiente historia:

En efecto, de repente, en el cielo sereno se vio menguar la luna. El soldado, que ignoraba la causa, lo tomó como un presagio concerniente al momento, igualando el eclipse del astro a sus fatigas, y suponiendo que la marcha de sus asuntos llegaría a buen final si la diosa recuperaba su brillo y claridad. Así, pues, bacen resonar el bronce y el clamor de tubas y cuernos; según la luna se volviera más clara o más oscura se alegraban o se entristecian; y cuando surgieron unas nubes que la ocultaban a la vista y la creyeron bundida en las tinieblas, con la propensión a la superstición que tienen tales mentes una vez que están impresionadas, se lamentaban de que se les anunciaba una fatiga sin fin, $y$ de que los dioses estaban disgustados por lo que babian becho (Ann. I 28, 1-2).

Una acción recordada por algunos sermones cristianos de la Edad Media empeñados en erradicar dicha costumbre. Así, Máximo de Turín se pregunta:

¿Quién de vosotros, hermanos, no se aflige (no me refiero ciertamente a todos, pues entre vosotros bay también algunos que podéis tomar como ejemplo de devoción), quién no se aflige, repito, al veros tan olvidados de vuestra salvación que pecáis incluso contra el cielo? Hace algunos días me habia enojado muchísimo contra vuestra excesiva avaricia, cuando, precisamente el mismo día, al atardecer, se levantó tal alboroto entre la gente, que llegó hasta el cielo. Al preguntar yo el porqué de tal griterío, se me contestó que aquellos gritos vuestros ayudaban a la luna en sus apuros y aquellos alaridos servian para detener su oscurecimiento. Me produjo risa tan necia creencia, de acuerdo con la cual como buenos cristianos le echabais una mano a Dios. Gritabais, en efecto, no fuera que, a causa de vuestro silencio, Él perdiera el astro, como si, impotente y débil, no fuera capaz de proteger las estrellas que Él ha creado, sin la ayuda de vuestros aullidos; vosotros, esforzados, hacéis bien asistiendo al Padre Eterno y ayudándole a regir los cielos. Pero, si queréis ser aún más útiles, debéis velar todas las tardes y todas las noches; pues cuántas veces, mientras vosotros dormíais, la luna babrá tenido que pasar sus apuros; sin embargo, nunca se ha caído del cielo. ¿O es que sólo pasa momentos críticos al oscurecery no en otros momentos o hacia el alba? Más bien será que entre vosotros, ha cogido la costumbre de pasar apuros sólo en las horas vespertinas, cuando tenéis el estómago cargado de una cena abundante y la cabeza trastornada por los excesos en la bebida (...). (Máximo de Turín, De defectione lunae, Sermo XXX; Corpus Christ. serie latina, vol. XXIII pp. 117-119). 
La eficacia de estos gritos, golpes de bronce y ruido en general en la lucha contra los espíritus malignos incide nuevamente en el origen de esta estructura ideológica, ya que es la misma táctica utilizada por las comunidades prehistóricas, o pueblos primitivos a la hora de avisar de la presencia de las fieras que los acechan por la noche, de ahuyentarlas e incluso en el momento de realizar expediciones comunitarias de caza.

La experiencia cotidiana mostraba a estas poblaciones la eficacia del griterío o del ruido en general a la hora de alertar a aquellos que duermen, ahuyentar a los depredadores, e incluso de encaminarlos a la trampa donde se le daría fin. Un recurso especialmente conveniente durante la noche, momento en el que la disminución del sentido de la vista de los hombres prehistóricos, les impedía utilizar otras armas contra sus depredadores. No es por tanto extraño que desde entonces el sonido de ciertos metales e incluso palabras, sea valorado como un eficaz recurso apotropeo contra los espíritus malignos.

Significativamente la mayoría de referencias de los autores clásicos a este tipo de acciones tienen como contexto la noche, momento en el que como vimos antes los dioses protectores duermen, circunstancia que nos lleva a plantear que tal conducta debió valorarse por numerosas personas como una función de aviso, intentando despertar y comunicar a los dormidos dioses protectores la llegada de los espíritus malignos.

\section{CONCLUSIÓN}

La oscuridad, bien por la llegada de la noche, por la presencia de una densa niebla, extinción de una llama, o por la ocultación del sol o luna a consecuencia de un eclipse, fue valorada por las sociedades antiguas como la máxima expresión de la ausencia de protección divina. Una desprotección, causada a veces por el sueño de los dioses y otras por la debilidad temporal de éstos frente a sus enemigos, aprovechada por los espíritus malignos para causar daño a los hombres.

\section{El ocaso}

He aqui la deliciosa noche, amiga del criminal; viene como un cómplice, con andares de lobo; el cielo se cierra lentamente como una gran alcoba, y el hombre impaciente se convierte en fiera. 
Oh noche, amable noche, deseada por aquel cuyos brazos, sin mentir, pueden decir: ¡Hoy hemos trabajado! La noche tranquiliza a los espiritus devorados por el dolor salvaje, al sabio obstinado cuy a frente se nubla, $y$ al obrero encorvado que vuelve a coger la cama.

Sin embargo, demonios malsanos en la atmósfera se despiertan lentamente, como hombres de negocios, $y$ al volar golpean los postigos y el alero.

A través de los resplandores de las luces que atormenta el viento se enciende la Prostitución en las calles; como un hormiguero abre sus salidas; por todas partes se hace camino a escondidas, igual que el enemigo que trata de atacar por sorpresa; Se mueve en el seno de la ciudad fangosa como un gusano que hurta al Hombre lo que come. Se oye aquí y allá silbar las cocinas, gritar en los teatros, retumbar las orquestas; las redondas mesas de juego se hacen las delicias, se llenan de rameras y de estafadores, sus cómplices, y los ladrones, sin tregua ni descanso, van pronto, ellos también, a empezar su trabajo, $y$ a forzar suavemente las puertas y las cajas fuertes para vivir unos días y vestir a sus queridas.

Recógete, alma mía, en este grave momento, y cierra tus oidos a todo este rugido.

¡Es la hora en que los dolores de los enfermos se hacen más agudos!

La sombría Noche los agarra del cuello; acaban su destino y van a parar a la sima común; se llena el hospital de sus suspiros. -Más de uno no irá ya a buscar la sopa bienoliente, junto al fuego, de noche, cerca de un alma amada. iAunque la mayoría no ba conocido nunca la dulzura del hogar y jámas ha vivido!

Ch. Baudelaire, Las flores del mal, n. 113. 


\section{REFERENCIAS}

Alvar, J. Los misterios. Religiones “orientales” en el Imperio Romano. Barcelona: Crítica, 2001, (452 p).

AriÈs, Ph., L'homme devant la mort. Paris: Seuil, 1977, (642 p).

Dauge, Y. A. Le Barbare. Reherches sur le conception romaine de la barbarie et de la civilisation. (Coll. Latomus, 176), Bruxelles: Latomus,1981, (859 p).

Deonna, W. Le Symbolisme de l’Oeil. Berne: Boccard,1965, (321 p).

Diez de Velasco, F. Los caminos de la muerte. Religión, rito e imágenes del paso al más allá en la Grecia antigua. Madrid: Trotta, 1995. (198 p).

Dölger, F. J. Die Sonne der Gerechtigkeit und der Schwarze. Eine religionsgeschichtliche Studie zum Taufgelöbnis. Münster: Westfalen, 1979 (1918). (172 p).

GIL, L. Therapeia. La medicina popular en el mundo clásico. Madrid: Triacastela, 2004 (1969). (553 p).

Giordano, O. Higiene y Buenas maneras en la Alta Edad Media. Madrid: Gredos, 2001, (170 p).

JOBBÉ-DUVAL, É. Les MORTS MALFAISANTS, “LARVAE, LEMURES”, D'APRÈS LE DROIT ET les Croyances populaires des Romains. Paris: Recuil Sirey, 1924. (334 p).

KIRK, G. S., RAVEN, J. E., SCHOFIELD, M. Los filósofos presocráticos, Madrid:Gredos, 2003 (Cambridge, 1957). (686 p).

Lunais, S. Recherches sur la Lune, I, Les auteurs latins de la fin des Guerres Puniques à la fin du règne des Antonins (EPRO, 72). Leiden: E. J. Brill, 1979, (414 p).

PASTOUREAU, M.. Negro. Historia de un color. Madrid: 451 editores, 2009, (210 p).

RUNCIMAN, S. La caída de Constantinopla. Madrid: Espasa-Calpe, 1973. (262 p). 
RUSSELL, J. B. El Diablo. Percepciones del mal, de la antigüedad al Cristianismo primitivo. Barcelona: Laertes, 1995. (282 p).

SAXER, V., Morts, martyrs, reliques en Afrique chrétienne aux premiers siécles. Les témoignages de Tertullien, Cyprien et Augustin à la lumière de l'archéologie africaine, Paris: Beauchesne, 1980. (340 p).

Wallraff, M., RAC, 23. Stuttgart: Anton Hiersemann, 2010, cols. 100-137, s.v. licht. 